of electronic structures was superseded by quantum mechanics, Pauli's principle found its natural place in it as the postulate that the wave function of several electrons is skew in the co-ordinates of these. Later, Pauli has shown the close connexion between his principle and the statisties of ensembles, namely, that particles with integral spin (photons, mesons) satisfy Bose-Einstein statistics, while particles with half-integer spin (electrons, protons) satisfy FermiDirac statistics.

Pauli also took part in the development of matrix mechanies. He was the first to treat the hydrogen atom by matrices, and he showed how in nonrelativistic approximation the spin of the electron could be represented by a set of matrices, so paving the way for Dirac's relativistic theory of the electron. He has published papers on nuclear physics (hyperfine structure), equilibrium of radiation and molecules, paramagnetism of metals, quantization of field equations (with Heisenberg), wave equations of particles with higher spin, entropy in quantum statistics, and similar subjects.

\section{Charles Chree Medal and Prize of the Physical Society: Dr. J. A. Fleming}

The Council of the Physical Society has awarded the third (1945) Charles Chree Medal and Prize to Dr. John A. Fleming; the presentation will be made on December 6. From about 1905 onwards, Dr. Fleming was the principal colleague of the late Dr. L. A. Bauer, the initiator and first director of the Department of Terrestrial Magnetism of the Carnegie Institution of Washington, whom he succeeded in 1932 as director and also as editor of the international journal Terrestrial Magnetism and Atmospheric Electricity. Dr. Fleming has been president of the International Association of Terrestrial Magnetism and Atmospheric Electricity of the Union of Geodesy and Geophysics since 1944 and general secretary of the American Geophysical Union from its inception.

Dr. Fleming's Department is the only institution in the world devoted to the study of terrestrial magnetism in all its aspects; and under him its work has been extended in new directions, including a wide programme of ionospheric study and both theoretical and experimental investigations in nuclear physics. The field-work undertaken by the Department has contributed greatly to the knowledge of the earth's magnetism where no magnetic surveys have been made and no permanent magnetic observatories exist. Much of this observational work was done under Dr. Fleming's direction; he controlled the organization and equipment of the teams of observers on land and shared in the design and the voyages of the non-magnetic ships Galilee and Carnegie, which made extensive magnetic surveys of the oceans for some twenty years, and in the planning and institution of the Department's magnetic observatories at Watheroo (Western Australia) and Huancayo (Peru). He has also helped and encouraged magnetic and atmospheric electric observa. tion by official or private agencies in many lands. But for his work our knowledge of the state of the earth's magnetic and electric fields during the past forty years would be materially less than it is. $\mathrm{He}_{\Theta}$ has also organized and stimulated the geomagnetic and electric researches undertaken by his Department, and notably in the elucidation of the short-lived magnetic effects associated with radio fade-outs and solar eruptions, and, in recent years, in radio science. Though it is not possible always to separate the work of Dr. Fleming from that of his staff, the unique position which the Carnegie Institution maintains in the investigations of all the problems of terrestrial magnetism is unquestionably due to his wise guidance and inspiring leadership.

\section{Science Museum :}

Retirement of Col. E. E. B. Mackintosh

THE many friends of Colonel E. E. B. Mackintosh will learn with regret of his retirement from the position of director and secretary of the Science Museum on November 30, on reaching the age limit. $\mathrm{H}_{\Theta}$ has held this position with distinction since 1933 , when he took over the directorship from Sir Henry Lyons, soon after the latter had successfully launched the Children's Gallery and introduced the idea of special exhibitions. He extended and developed both these features, and by 1939 had succeeded in evolving an attractive and fascinating gallery, specially designed and arranged for the younger visitors, and providing a most instructive elementary introduction to many branches of science. $\mathrm{H}_{\theta}$ has explored the possibilities of different types of special exhibition, and for a number of years has devoted one of the main galleries of the Museum entirely to this purpose. During the period 1933-39, some thirty-five special exhibitions were held in the Museum, not a few of which met with outstanding success, and there is no doubt that the policy of holding these special exhibitions has been well justified. Under Colonel Mackintosh's direction, the Science Museum continued to maintain and even to improve its position in the forefront of the national museums and galleries of Britain, until the War necessitated its closure. The main task of the Museum at this time was to ensure the safety of its contents-objects, archives and records alike-and Colonel Mackintosh succeeded in dispersing approximately two thirds of the collection, together with more than 100,000 volumes from the Science Library, to thirty isolated country houses. A selection of these possessions is now being brought back to London, in preparation for the partial reopening of the Museum. Colonel Mackintosh will have the good wishes of his many friends in his well-earned retirement.

Dr. H. Shaw

THE Ministry of Education has announced the appointment of Dr. Herman Shaw as director and secretary of the Science Museum as from December I in succession to Colonel E. E. B. Mackintosh. The appointment of a professional man of science to this important office is a departure from past practice, and will be generally welcomed. Dr. Shaw received his education at Bradford Grammar School and the Royal College of Science, where he studied physics. During the First World War he served in the Royal Naval Air Service. He joined the staff of the Science Museum in 1925, and later became 'keeper' of physics. His special interest in physical research has been in geophysics, and he was awarded the degree of D.Sc. of the University of London for a geophysical research using the Eötvös pendulum. He has long been associated with the Physical Society, of which at present he is the acting treasurer; he also took an active share in the organization of the Edinburgh meeting of the International Union for Geodesy and Geophysics in 1936. 